\title{
A FIFA Fan Fest e as diferentes formas de consumo do produto futebol durante a Copa do Mundo 2014: socialização, pertencimento e entretenimento
}

\section{The FIFA Fan Fest and the different forms of product consumption soccer during the World Cup 2014: socialization, belonging and entertainment}

\begin{abstract}
Yuri Spacov | Universidade Nove de Julho (UNINOVE) Mestre em Gestão do Esporte pelo Programa de Mestrado Profissional em Administração-Gestão do Esporte da Universidade Nove de Julho (MPA-GE/UNINOVE)

E-mail: yurispacov@gmail.com
\end{abstract}

Ary José Rocco Jr | Escola de Educação Física e Esporte da Universidade de São Paulo (EEFE/USP) Doutor em Comunicação e Semiótica pela Pontíficia Universidade Católica de São Paulo (PUC/SP), com Pós Doutorado em Ciências da Comunicação pela Escola de Comunicações e Artes da Universidade de São Paulo (ECA/USP), Professor da Escola de Educação

Física e Esporte da Universidade de São Paulo (EEFE/USP)

E-mail: aryrocco@usp.br

\begin{abstract}
Marcos V. Cardoso | Universidade Nove de Julho (UNINOVE) Professor do Programa de Pós-Graduação em Administração-Gestão do Esporte (MPA-GE) e do Mestrado e Doutorado em Informática e Gestão do Conhecimento (PPGI) da Universidade Nove de Julho (UNINOVE)

E-mail: mvcardoso@gmail.com
\end{abstract}

Lucas Cardoso dos Reis | Universidade Nove de Julho (UNINOVE) Mestre em Administração-Gestão do Esporte pelo Programa de Pós-Graduação em Administração-Gestão do Esporte da Universidade Nove de Julho (MPA-GE/UNINOVE) E-mail: lucasreis.lucas@gmail.com

\begin{abstract}
Resumo
O objetivo deste artigo é apontar e analisar os principais fatores que levaram uma pessoa, ou um grupo de pessoas, a assistir um jogo de futebol da Copa do Mundo 2014 em uma FIFA Fan Fest e não em outros locais. Socialização, afetividade e diversão são aspectos considerados na análise. $\mathrm{O}$ papel do esporte enquanto produto de entretenimento e consumo também foi contemplado no estudo. $\mathrm{O}$ evento, pela proliferação de imagens que proporciona, é exemplo claro do que Guy Debord definiu como Sociedade do Espetáculo. Foram entrevistadas 79 pessoas em duas FIFA Fan Fests realizadas na cidade de São Paulo, em partidas da seleção brasileira na Copa do Mundo 2014. Os resultados obtidos no estudo comprovam a inserção do esporte mais popular do planeta na lógica das modernas estratégias de consumo. Também evidenciam as relaçóes existentes entre o futebol, e seu universo, e a chamada indústria do entretenimento. Palavras-Chave: Comportamento do consumidor; Copa do Mundo; FIFA Fan Fest
\end{abstract}




\begin{abstract}
The purpose of this article is to analyze the main factors that led a person, or a group of people, to watch a football match of 2014 World Cup in a FIFA Fan Fest and not elsewhere. Socialization, affection and fun aspects are considered in this analysis. The role of sport as an entertainment and consumption product was also contemplated in this study. The event, with images proliferation that provides, is a clear example of what Guy Debord defined as the Spectacle Society. 79 people were interviewed in two FIFA Fan Fests held in São Paulo during Brazilian National team in the 2014 World Cup. The results of this study confirm the insertion of the most popular sport in the planet in the logic of modern consumption strategies. Also show the relationship between football, and his universe, and the entertainment industry.
\end{abstract}

Keywords: Marketing; 2016 Olympics; favela clearance

\title{
Introdução
}

A FIFA Fan Fest, evento criado pela FIFA, entidade que regulamenta, organiza e dirige o futebol em todo o mundo, durante a Copa do Mundo FIFA 2006, realizada na Alemanha, é uma poderosa ferramenta de marketing para a entidade e, também e principalmente, para seus patrocinadores. A "festa", realizada no espaço público de cidades espalhadas pelo mundo, durante a disputa da Copa do Mundo, fortalece o contato da FIFA, e dos seus patrocinadores, com consumidores dos seus produtos em todo o planeta.

Em 2010, durante a Copa do Mundo disputada na África do Sul, mais de seis milhôes de fâs participaram das FIFA Fan Fests, realizadas em 16 cidades de cinco continentes durante os 31 dias da competiçâa. Com identidade visual e estratégia de comunicação própria desenvolvidos para o evento, as celebraçóes dessas "festas" da FIFA atingem, a cada edição da Copa do Mundo, audiência maior. Para a FIFA, o objetivo das Fan Fests é claro: criar um segundo lugar, além dos estádios, para que os torcedores de todo o mundo compartilhem experiências, tenham interação com a competição, marcas e patrocinadores, celebrando a atmosfera única que somente a Copa do Mundo fornece (FIFA, 2014b).

Realizadas ao ar livre, no espaço público das cidades-sede da Copa do Mundo de 2014, as Fan Fests organizadas no Brasil durante a disputa da competição mais importante do futebol mundial, em 2014, extrapolaram o ambiente dos novos estádios e arenas construídos para a disputa. Como uma extensão dos locais onde as partidas aconteceram, as Fan Fests levaram os jogos da Copa do Mundo, de forma gratuita, para espaços públicos tradicionais das cidades brasileiras, sedes da competição. Em São Paulo, por exemplo, as "festas" organizadas e promovidas pela FIFA aconteceram no Vale do Anhangabaú, tradicional local de manifestaçóes populares da capital paulistana. No Rio de Janeiro, a praia de Copacabana foi o local escolhido para as Fan Fests cariocas.

Com estrutura que evidencia os patrocinadores da Copa do Mundo, as Fan Fests exibiram as principais partidas da competição ocorrida no Brasil, mas também abrigaram shows com artistas locais, oriundos da própria cidade onde o evento 
ocorreu. Uma clara combinação entre o global e o local. Um espaço amplo para entretenimento e convivência social. Forte relação simbólica com a cidade e com o esporte pode ser medida em escala de dependência e identidade com o local onde ocorreram (WILLIAMS; PATERSON; ROGGENBUCK; WATSON, 1992).

Em balanço divulgado pelo Ministério do Esporte (2016), ao final da Copa do Mundo 2014, o público total que frequentou as FIFA Fan Fests nas doze cidades-sede da competiçáo foi de 5,15 milhóes de pessoas durante a disputa do Mundial. Somente na cidade do Rio de Janeiro, onde o evento aconteceu na praia de Copacabana, mais de um milhão de pessoas $P A S$ saram pela "festa" durante a Copa do Mundo. (EBC, 2014).

Apesar do seu sucesso como estratégia de marketing para a entidade que organiza o futebol no mundo, a FIFA, a Fan Fest representa, na concepção do teórico marxista francês Guy Debord (2000), a alienação social. Funcionando como uma simulação ou representação da realidade, este tipo de evento aliena o indivíduo da realidade social.

O filósofo francês defende a ideia de que eventos como a Fan Fest criam uma separação entre as classes de pessoas que podem participar do evento original, como o jogo disputado em um estádio de futebol, das pessoas que, sem condição de ir às praças esportivas, vão às Fan Fests.

As Fan Fests significam, assim, verdadeiras representações ou simulaçôes simbólicas das partidas realizadas em uma arena ou estádio de futebol localizado a quilômetros de distância de onde se celebra a Fan Fest. São elementos constitutivos daquilo que o pensador francês chamou de "Sociedade do Espetáculo" (DEBORD, 2000).

O esporte como fenômeno social transcendeu seus papeis de socialização, afetividade e cognição. O futebol, por exemplo, é hoje um dos vértices da chamada indústria do entretenimento. Além da paixão por modalidades esportivas, os indivíduos procuram, cada vez mais, enquanto espectadores dos eventos esportivos, diversão, lazer e entretenimento. $\mathrm{O}$ futebol, em especial, por sua popularidade no Brasil, movimenta multidôes em varias regióes e cidades do país. Elemento de identificação da identidade nacional, o futebol $P A S$ sou a atrair a atenção do mercado, como produto ideal para consumo do entretenimento e da diversão, nos momentos de lazer dos torcedores e fãs do esporte.

Vários fatores são ponderados na hora do individuo escolher assistir uma partida da Copa do Mundo em uma Fan Fest, em detrimento de outros locais, como o próprio estádio onde ocorre o jogo, num bar com seus amigos ou no conforto de sua residência. Questóes como pertencimento social, apego afetivo e diversão vão ao encontro da paixão por um esporte (THEODORAKIS; WANN; CARVALHO; SARMENTO, 2010), neste caso, o futebol.

O objetivo deste artigo é apontar e analisar os principais fatores que levaram uma pessoa, ou um grupo de indivíduos, a assistir um jogo de futebol da Copa do Mundo 2014 em uma Fan Fest da FIFA e não em outros locais. As Fan Fests são eventos alienantes, como afirmava Debord (2000) ou representam um excelente local para confraternizar e comemorar com outras pessoas? 
Para a pesquisa de campo foi aplicado questionário estruturado em escala Likert de cinco pontos, com opçóes escalonadas do discordo totalmente (1) até o concordo totalmente (5). O local de coleta foi a Fan Fest instalada no Vale do Anhangabaú em São Paulo. A amostra estudada foi composta por 79 entrevistados, frequentadores do evento, em dois jogos da Seleção Brasileira pela Copa do Mundo de 2014: a partida de abertura, entre Brasil e Croácia, e o jogo pelas quartas de final, disputado entre Brasil e Colômbia.

Para formulação da ferramenta de coleta de dados, foi utilizado o Place Attachment Scale (PAS) (WILLIAMS at al., 1992). O PAS auxilia no estudo da vinculaçáo emocional entre o individuo e o local frequentado, no caso a Fan Fest. $\mathrm{O}$ modelo é influenciado pelas experiências individuais e procura estabelecer as relaçóes entre o significado e as preferências, para o individuo, em estar ou não no local pesquisado, em detrimento de outras opçóes de lugares a ser frequentados (WILLIAMS et al., 1992). Após a realização do estudo, foi possível identificar a interação entre três dimensôes do $P A S$ : dependência do local, sua identidade e as relaçôes sociais.

Os resultados levaram à interessante discussão dos fatores relacionados a apego social, dependência e identidade do local, atrelados ao esporte como entretenimento. Tais elementos conduzem as motivaçóes dos indivíduos a perceberem a Fan Fest da FIFA como local ideal para assistir uma partida da Seleção Brasileira de futebol durante a Copa do Mundo 2014. Contribuem, assim, para o entendimento do place attachament - apego ao local - em eventos esportivos gratuitos que utilizam o entretenimento como centro de atração e interação social.

\section{As Fan Fests, a Sociedade do Espetáculo e o consumo do produto futebol}

Para a Copa do Mundo de 2014, no Brasil, o modelo adotado pela FIFA para estruturação das Fan Fests, em acordo com as autoridades governamentais do país, foi a da organizaçáo do evento em parceria entre as cidades-sede e a organização que controla o futebol mundial. Para ser cidade-sede da Copa do Mundo, as prefeituras municipais assumiram o compromisso, em contrato assinado com a FIFA, de estruturar as "festas" em locais adequados e propícios para isso.

Para ser uma área oficial da FIFA era preciso apresentar os seguintes requisitos: (1) entrada gratuita e local seguro a todos os visitantes; (2) todos os 64 jogos da competição transmitidos ao vivo; (3) os espaços deveriam reproduzir a atmosfera de um estádio de futebol; (4) telóes gigantes de alta qualidade e sistemas de som e de luz que garantiriam ótima experiência ao público ao assistir o jogo (FIFA, 2014a). Antes e depois das transmissóes das partidas o palco e a enorme tela foram utilizados para entretenimento, com a apresentação de artistas locais. Produtos licenciados, comidas e bebidas estiveram disponíveis no local. A FIFA Fan Fest é mais do que um local onde as pessoas se reúnem para assistir a uma partida de futebol. É um lugar onde os fấs "experimentam" o esporte com o objetivo principal de reproduzir o ambiente vivido dentro do estádio, com o mesmo tipo de torcedores, segurança e conforto (BORGES, 2013). 
O futebol apresenta, atualmente, uma dimensão global e a cultura que o cerca ocupa um lugar especial na moderna indústria mundial de consumo. A ânsia pelo entretenimento instantâneo é consequência da sociedade de consumo e de sua fragmentação. Os produtos culturais, como o futebol e a música, por exemplo, são feitos para serem rapidamente consumidos a fim de que novos sejam produzidos (ROCCO JR, 2011). A combinação do futebol e do entretenimento, com a realização dos shows, são os principais ingredientes da FIFA Fan Fest. Todos esses elementos constituem aquilo que o pensador marxista francês Guy Debord (2000) definiu como "Sociedade do Espetáculo".

O conceito central da sociedade do espetáculo de Debord é que a alienação é mais do que uma descrição das emoçôes de um indivíduo ou de um aspecto psicológico. É o resultado do modo capitalista de organização social que assume novas formas e conteúdos no processo de reificação da vida humana (DEBORD, 2000).

No entender do francês (DEBORD, 2000), a FIFA Fan Fest é uma representação moderna de um novo produto econômico oferecido ao consumidor individual. Para o pesquisador, as pessoas preferem hoje a imagem e não a coisa real, a cópia ao original, a representação à realidade, a aparência ao ser (DEBORD, 2000). A FIFA Fan Fest é, assim, uma reprodução de uma partida original que é jogada em um estádio ou arena a quilômetros de distância de onde ocorre a Fan Fest. A relação do público com o esporte é mediada por imagens em uma tela gigante com altíssima definição para melhorar a qualidade do espetáculo em uma verdadeira simulação do evento original.

Tais eventos, inseridos dentro do contexto da sociedade do espetáculo trazem até os indivíduos, frequentadores das Fan Fests, tudo aquilo que falta em sua dura vida cotidiana de pessoas comuns: celebridades, atores, esportistas de sucesso, gurus e a publicidade. Tudo transmite uma sensação de constante aventura, felicidade, grandiosidade e ousadia. É a forma mais elaborada do extremo "fetichismo da mercadoria", no caso aqui exemplificada pelo produto Copa do Mundo. Assim, as relações entre as pessoas são transformadas em imagens e espetáculo (DEBORD, 2000).

Debord (2000) reforça seu ponto de vista ao afirmar que a vida nas sociedades modernas de produção é, em si, uma imensa acumulação de espetáculos. Tudo o que foi vivido diretamente afastou-se em uma representação. A Fan Fest é o show sobre o show. É a simulação de uma celebração que tem seu lugar no topo do espetáculo original, neste caso, os estádios e arenas do país onde aconteceram as partidas da Copa do Mundo 2014, todas disputadas quilômetros de distância dos locais das Fan Fests.

O ambiente da Fan Fest representa um espaço onde as pessoas consomem uma simulação da realidade (Baudrillard, 1998). Os fấs presentes ao evento são, em todos os momentos, bombardeados por imagens e sons que nada mais são do que uma representação da realidade que ocorre em um lugar distante. O principal objetivo do evento não é o jogo, mas o consumo do produto futebol, criando uma atmosfera voltada para esse fim. 
Uma das características da cultura da sociedade pós-moderna, que Debord (2000) define como sociedade do espetáculo, é, segundo vários de seus estudiosos, como Fredric Jameson (2005), Mike Featherstone (1995), Zygmunt Bauman (2001) e Jean Baudrillard (1992), a de ser uma sociedade-cultura de consumo. Esse tipo de sociedade, que caracteriza o momento em que vivemos, reduz o indivíduo à condição de consumidor como consequência da automatização do sistema de produção.

Os novos formatos do consumo nessa sociedade, ilustrados pelas Fan Fests, estão relacionados com os meios de comunicação, com a alta tecnologia, com as indústrias da informação (buscando expandir uma mentalidade consumista, a serviço dos interesses econômicos) e com as maneiras de ser e de ter do homem pós-moderno (JAMESON, 2005).

O modo de produção e de circulação dos bens, os padróes de desigualdade no acesso aos bens materiais e simbólicos, a maneira como se estruturaram as instituiçôes da vida cotidiana (como a família, o lazer, os ambientes urbanos, etc.), estão, em última instância, relacionados com o consumo (FEATHERSTONE, 1995). Nossa sociedade-cultura cria, constantemente, novos espaços para os consumidores, tornando o consumo um sistema global que molda as relaçóes dos indivíduos na pós-modernidade e é reconfigurada por tecnologias variáveis que determinam os padróes de consumo (JAMESON, 2005).

Jean Baudrillard (1992), por exemplo, afirma que, nessa sociedade pós-moderna, "já não consumimos coisas, mas somente signos". Dentro desse contexto, a estetização da vida cotidiana e o triunfo do signo retratam a subordinação da produçáo ao consumo sob a forma de marketing, com uma ascensão cada vez maior do conceito de produto, do design e da publicidade (BAUDRILLARD, 1992). A pluralidade de consumidores é considerada através de um processo governado pelo jogo da imagem, do estilo, do desejo e dos signos e distribui-lhes estilos de vida de acordo com os critérios de mercado (JAMESON, 2005).

Para Giddens (2002), a mercantilização do consumo participa diretamente dos processos da contínua reformulação das condiçôes da vida cotidiana, gera a chamada "experiência mercantilizada" da vida, e estimula o crescimento econômico ao estabelecer padróes regulares de consumo promovidos pela propaganda e outros métodos.

Como resultado da produçấo existe uma "lógica do capital", nesta sociedade-cultura pós-moderna existe uma "lógica do consumo", estruturada em torno do simulacro, do hedonismo, da colagem, do "tudo vale", da efemeridade, etc (BAUDRILLARD, 1992). Nesta lógica consumista, tudo é feito no sentido de atrair o consumidor; as imagens desempenham um papel importante, sendo constantemente veiculadas pela mídia (GIDDENS, 2002).

Em função disso, Featherstone (1995) afirma que "o consumo, não deve ser compreendido apenas como consumo de valores de uso, de utilidades materiais, mas primordialmente com o consumo de signos". Esse processo mencionado pelo pesquisador desestabiliza "a noção original e torna as mercadorias 
verdadeiras ilusóes culturais, que fascinam o consumidor pós-moderno pela sua estética, pelas associaçóes mirabolantes com os signos e pelas justaposiçóes entre elas" (FEATHERSTONE, 1995).

Justifica-se então o privilégio dado pelo capitalismo pós-moderno à produção de signos e imagens, ao invés das próprias mercadorias. Esta dinâmica está totalmente vinculada à capacidade de rapidez do mercado em explorar novas possibilidades e na sua rapidez em apresentar novos produtos, criar novas necessidades e novos desejos (HARVEY, 1992). As Fan Fests são exemplos visíveis do que afirma Harvey (1992).

\section{As Fan Fests, a diversidade cultural e a vinculação com o local do evento}

Neste cenário, as preferências de consumo - e o estilo de vida - estão relacionadas a uma rígida estrutura de distinçôes graduais que operam na sociedade. A dinâmica desta estrutura pressiona o indivíduo a adquirir bens que lhe atribuirão posição, mercadorias altamente conceituadas por seus pares e que, portanto, lhe atribuirão determinado status. Consumir o produto Copa do Mundo, mesmo que na singular forma da Fan Fest, já que ir ao estádio não é possível, é também participar do evento e contar com o status de que tal consumo propicia ao seu consumidor.

O enfraquecimento da identidade local e a composição desta individualidade uniforme moldada por uma cultura global e que implica na adoção de padróes de vida e consumo vinculados a países altamente industrializados. Tudo isso motiva o indivíduo a se distanciar de valores locais e solidários. Porém, e em determinadas circunstâncias, a cultura local, típica da modernidade, ressurge com força. Tudo em nome da cultura do consumo do produto esporte.

Claussen, Ko \& Rinehart (2008) invocam esse argumento através das teorias da diversidade cultural para ilustrar as diferenças existentes entre local e global. Para os autores, o produto FIFA Fan Fest é a representação máxima da homogeneidade global de consumo patrocinado pela FIFA e pelos seus investidores e parceiros comerciais. $\mathrm{O}$ evento, realizado e consumido simultaneamente em várias partes do mundo, como ocorreu em 2006 e 2010, representa essa padronização da marca FIFA e dos seus patrocinadores.

No entanto, para uma estratégia global desse porte funcionar adequadamente, a entidade que dirige o futebol deve levar em conta as diferenças locais. Antes e depois da transmissão de cada jogo, a programação das Fan Fests incluíram concertos de música popular e atividades culturais totalmente identificados com cada uma das cidades-sede que promoveram o evento. É o local dentro do global; a porção dentro do conjunto; a diferença na integração; a pluralidade dentro da homogeneidade (CLAUSSEN et al., 2008).

O esporte carrega fortes influências sociais e culturais, estabelecendo um comportamento de consumo peculiar. Influências internas como estado psicológico, emoção e envolvimento com o esporte, convivem com influências externas como amigos, ídolos, família e ambiente. Essa combinação conduz os indivíduos à relação de consumo com produtos e serviços esportivos (SUMMERS; MORGAN, 2005). 
O consumo aborda aspectos socioculturais, experienciais, simbólicos e ideológicos, gerado em co-produção com os consumidores, trabalhando com marketing gerados por materiais e significados (ARNOULD; THOMPSON, 2005). Neste sentido, a sociedade industrializada não é diferente de qualquer outra sociedade, hegemônica e etnocêntrica, levando grupos e indivíduos a satisfazerem necessidades de experimentar formas diferenciadas de consumo (BELK; WALLENDORF; SHERRY, 2006), muito semelhante à fidelização, promovendo entendimento para determinadas atitudes do consumo esportivo.

A diversidade cultural é uma noção complexa que implica diferenças entre tipos, incluindo atributos físicos (e.g.; raça, sexo, idade, capacidade física), atributos sociais (e.g.; educação, nível de renda) e atributos culturais (e.g.; crenças, valores, preferências). De uma perspectiva do marketing, temos também a psicografia (e.g.; preferências de estilo de vida, atitudes, valores, traços psicológicos e construtos motivacionais), além das questóes demográficas (CLAUSSEN et al., 2008).

Todos esses elementos devem ser considerados na elaboração de estratégias mercadológicas para abranger e contemplar a compreensão da diversidade no comportamento do consumidor. Assim, a diversidade é definida como a presença de diferenças entre os membros de uma unidade social que levam à percepção de tais diferenças e atitudes únicas de consumo (CLAUSSEN et. al, 2008). Essa diversidade vem ao encontro da constituição cultural de cada indivíduo. A identidade, relação com ambiente e conexão social também incorrem sobre atitudes e comportamentos de consumidores dos produtos esportivos.

A FIFA Fan Fest é, assim, o produto futebol em embalagem de entretenimento. Almeja, com isso, transformar um local público qualquer, através da criação de uma atmosfera única, em um estádio de futebol. O sentido de lugar, psicológico ou unidade percebida de um ponto geográfico, o local, é responsável pela construção de uma experiência sensitiva para os presentes. Locais físicos se transformam em locais significativos quando há conexão forte de identidade e dependência, podendo ser uma região geográfica, um lar, vizinhança, cidade ou nação (WILLIAMS et al., 1992).

A fim de estudar esses vínculos com locais, alguns modelos foram propostos primeiramente conceituando duas dimensôes de vínculo: (1) dependência do local - place-dependence —; (2) identidade do local — place-identity - (WILLIAMS et al., 1992).

Ao aprofundar as duas dimensões que formam o conceito de vínculo com o local — place attachment — temos: (1) dependência do local — place-dependence: refere-se a importância do local em promover características e condiçóes específicas para atividades desejadas. Relacionado à função que o local proporciona e seu poder de insubstituição e inseparabilidade; (2) identidade com o local - place-identity, relacionado a emoção que o local provoca, refere-se a importância simbólica do local como fonte de emoções e relações que gera a satisfação pessoal (WILLIAMS; VASKE, 2003). Surge, com base nessas duas dimensóes, uma proposta de escala 
para mensurar o vínculo que o indivíduo possui com o local - PAS: Place attachment scale - e o que essa escala representa na análise do comportamento do consumidor.

Theodorakis et al. (2010) chamam a atenção para a relação existente entre os locais com movimentação turística e o esporte como elemento motivador para que consumidores realizem viagens ao redor do mundo. Esses autores foram os responsáveis pela tradução e pela adaptação do PAS Place Attachment Scale para o português. Além das dimensóes originariamente propostas, inseriram novas dimensóes no modelo: além de (a) dependência do local — place-dependence - e (b) identidade do local — place-identity; os pesquisadores incluíram duas novas dimensóes: (1) relação social (amigos, familiares, necessidade de socialização) - social bond - e (2) vínculo afetivo - affective atachment. Assim, o PAS foi traduzido e validado para o $P A S$-p, em português.

No entanto, investigaçóes adicionais devem ser conduzidas de modo a melhorar e determinar a validade do construto para o português (THEODORAKIS et al., 2010). É por essa razão que, para o presente estudo, o modelo do PAS Place Attachment Scale utilizado foi baseado no estudo de Budruk (2010) — estudo confirmatório de Place Attachment —, que utiliza apenas três dimensôes para mensurar o vínculo dos consumidores com o local: (1) dependência do local — place-dependece, (2) identidade do local - place-identity, e (3) relação social — social bond.

Essas três dimensões se relacionam fortemente com a formação do vínculo gerado psicologicamente com o local. Ocasionalmente, conceitos que são aparentemente universais podem ser entendidos de forma diferenciada em outra cultura ou idioma (BUDRUK, 2010).

\section{Métodos e técnicas}

Este estudo buscou investigar os principais fatores que motivaram as pessoas a frequentarem as FIFA Fan Fests, realizadas na cidade-sede de São Paulo, para assistir a uma partida da Seleção Brasileira de futebol, durante a realização da Copa do Mundo de 2014. A intenção foi identificar os elementos que mais incidiram nessa procura pelas Fan Fests como elemento de consumo do produto Copa do Mundo: questóes sociais e culturais, a busca pelo entretenimento ou o gosto pelo futebol. Assim a questão de pesquisa seria "Quais desses elementos/ambientes estiveram conectados, direta ou indiretamente, com a decisão do indivíduo de ir a uma FIFA Fan Fest?".

A pesquisa realizada para esse estudo completo foi de natureza quantitativa. Porém, para a realização deste artigo, optamos por trabalhar com as análises qualitativas dos dados obtidos.

Foram realizadas entrevistas no Vale do Anhangabaú, centro da cidade de São Paulo, utilizando instrumento de pesquisa, questionário, adaptado do $P A S$. Foi nesse local que a Prefeitura do Munícipio de São Paulo e a FIFA instalaram a Fan Fest na cidade durante a realizaçáo da Copa do Mundo de 2014. Foram entrevistadas 79 pessoas em dois jogos da Seleção Brasileira. As 
partidas escolhidas para a realização da coleta foram: o jogo de abertura da Copa do Mundo entre Brasil e Croácia e a partida válida pela disputada das quartas de final da competição entre Brasil e Colômbia.

Os jogos da Seleção Brasileira em Copa do Mundo são aqueles que despertam interesse quase que total da população do país. Os amigos se reúnem, promovem encontros, combinam programas para assistir a jogos do Brasil nesse tipo de competição. Por causa desses elementos, e da importância das partidas consideradas, que os jogos da Seleção Brasileira foram escolhidos para a coleta dos dados.

São em partidas dessa natureza que os consumidores fazem suas opçóes em torno da escolha de como um mesmo produto - o jogo da Seleção Brasileira - será consumido, dentro dos diversos formatos oferecidos pelo mercado: no estádio, na Fan Fest, no cinema (durante a Copa do Mundo 2014, as principais partidas foram transmitidas também no cinema), no bar com os amigos, no conforto de sua residência, entre outros.

O instrumento de pesquisa foi elaborado com base no estudo de Budruk (2010) com o modelo PAS Place Attachment Scale, que utiliza três dimensóes para mensurar o vínculo com o local. As questóes do instrumento, de acordo com o propósito do estudo, foram divididas em três dimensóes:

(1) dependência do local - place-dependece:

- Assistir a uma partida de futebol em uma Fan Fest é melhor do que assistir à mesma partida em um bar;

- Assistir a uma partida de futebol em uma Fan Fest é melhor do que assitir à mesma partida no aconchego de minha casa; e,

- Assistir a uma partida de futebol em uma FanFest é melhor do que ir a um estádio de futebol

(2) identidade do local — place-identity:

- Interesse pessoal por Fan Fests

- Interesse pessoal por futebol

- Gosto de entretenimento

- Qualidade do jogo que será exibido

- Qualidade dos shows que acontecerão no evento

(3) relação social — social Bond:

- O tipo de pessoas que vão assistir aos jogos nas Fan Fests

- Comportamento da plateia nas Fan Fests durante os jogos

- Sensação de pertencimento (companhia dos amigos)

- Ausência de torcedores organizados

Para o questionário foi utilizado a escala Likert de 1 a 5 , com " $1=$ Discordo totalmente" a "5 = Concordo totalmente". Para cada pergunta, os entrevistados deveriam indicar apenas uma única opção. 


\section{Resultados e discussão}

$\mathrm{O}$ estudo procurou investigar os principais fatores que motivaram indivíduos a frequentar as FIFA Fan Fests, realizadas na cidade São Paulo, durante a Copa do Mundo de 2014, em especial em jogos da Seleção Brasileira.

Os resultados obtidos na amostra coletada demonstram que houve interação entre as três dimensóes do Place Attachment Scale: (1) dependência do local — place-dependece; (2) identidade do local - place-identity; e, (3) relação social - social Bond.

Do ponto de vista da dependência do local, foi possível constatar que assistir a uma partida de futebol em uma Fan Fest é considerado, por parte da amostra coletada, como uma experiência superior a assistir ao mesmo jogo em um bar ou no aconchego do lar. Para as pessoas entrevistadas, acompanhar uma partida de Copa do Mundo nas "festas" da FIFA só perde, enquanto experiência, para ir a um estádio de futebol.

$\mathrm{Na}$ amostra pesquisada, $77,2 \%$ concordaram totalmente $(58,2 \%)$ ou concordaram (19,0\%) que assistir a uma partida de futebol em uma Fan Fest é melhor do que assistir à mesma partida em um bar. Apenas 5,1\% discordaram totalmente da afirmação.

Quando perguntados sobre a comparação entre as "festas" da FIFA e o aconchego de seu lar, 76,0\% concordaram totalmente (51,9\%) ou concordaram $(24,1 \%)$ que ver um jogo de futebol em uma Fan Fest é melhor do que presenciar ao mesmo jogo no conforto de seu lar. Apenas 8,8\% discordaram totalmente do enunciado.

Porém, quando a comparação realizada foi entre as Fan Fests e os estádios de futebol, os entrevistados deixaram claro que assistir a uma partida de futebol em um estádio é experiência considerada de natureza superior em comparação com as "festas" da FIFA. Para a amostra coletada, 59,5\% discordaram totalmente $(48,1 \%)$ ou discordaram $(11,4 \%)$ que assistir a um jogo em uma Fan Fest é melhor do que assistir ao mesmo jogo em um estádio de futebol. Importante frisar que, mesmo assim, 17,7\% concordaram totalmente que a experiência da Fan Fest é melhor, inclusive, do que a obtida na ida a um estádio para ver o mesmo jogo.

Os dados obtidos permitiram confirmar o sucesso da estratégia de mercado da FIFA ao revestir um mesmo produto, a Copa do Mundo, de outra "roupagem", a da Fan Fest, para ampliar suas possibilidades de extensão de consumo e de ampliação dos benefícios aos seus patrocinadores/investidores.

A promoção e realização das Fan Fests ampliam as possibilidades de consumo do produto Copa do Mundo, em especial para torcedores que não conseguiram frequentar os estádios e arenas, espaço onde o produto original foi produzido e consumido. Os resultados que confirmaram essa hipótese reforçam o caráter de consumo do produto futebol, defendido por autores como Guy Debord (2000), Fredric Jameson (2005), Mike Featherstone (1995), Zygmunt Bauman (2001) e Jean Baudrillard (1992), todos apresentados acima. 
Com relação à identidade do local, os dados obtidos apontaram a qualidade da partida que será exibida como principal fator de motivação para a ida a uma Fan Fest. Dos torcedores entrevistados, 91,2\% apontaram a qualidade do jogo que será exibido como elemento de comparecimento à "festa”. Por outro lado, 53,1\% afirmaram levar em consideração a qualidade dos shows e atraçóes culturais do evento para ir a uma Fan Fest. $\mathrm{O}$ futebol, pelo menos na cidade de São Paulo, foi a principal atração e elemento de motivação para a presença de público nas Fan Fests da FIFA.

Por outro lado, e de forma contrastante, $92,4 \%$ afirmaram que vão ao evento para se divertir. Contingente um pouco menor, $85,9 \%$, indicaram que comparecem às Fan Fests para torcer. A atmosfera criada pela FIFA no local foi apontada por $93,7 \%$ da amostra como um dos principais elementos de atração das "festas". A grande maioria dos entrevistados, 95,0\%, concordou com a afirmação de que as Fan Fests são uma verdadeira experiência de entretenimento.

As FIFA Fan Fests se converteram, assim e pelos resultados obtidos, em locais excelentes para as pessoas acompanharem uma partida de futebol da Copa do Mundo 2014, com diversão e torcida. As analises dos dados obtidos demostraram, também e como já mencionado, a excelência das Fan Fests como ferramenta mercadológica estratégica da FIFA para o consumo do produto Copa do Mundo.

Todos os fatores apontados acima indicam, de forma clara e objetiva, que vivemos hoje aquilo que Guy Debord definiu quatro décadas atrás como "Sociedade do Espetáculo" e que os principais produtos esportivos são, hoje, parte integrante da indústria do entretenimento e do consumo.

Com relação à dimensão social, os dados obtidos apontaram para forte busca de sociabilização, como motivação principal para os indivíduos irem às Fan Fests na cidade de São Paulo durante a Copa do Mundo FIFA 2014.

Fatores como segurança do local $(92,2 \%)$, comportamento das pessoas presentes ao evento $(84,8 \%)$, sensação de pertencimento $(83,3 \%)$, tipos de pessoas que frequentaram as festas $(82,1 \%)$, conforto do local $(70,8 \%)$ e ausência de torcidas organizadas $(67,1 \%)$ foram apontados pela amostra como elementos positivos das Fan Fests da FIFA.

Como resultado final, 96,2\% dos entrevistados afirmaram que recomendariam a experiência de assistir um jogo da Copa do Mundo em uma Fan Fest para seus amigos e $84,6 \%$ apontaram que pretendiam repetir a experiência ainda durante o Mundial no Brasil.

Os resultados obtidos evidenciaram que a sensação de pertencimento a um grupo, experimentada nas Fan Fests, funcionou como elemento de motivação para o individuo consumir o produto Copa do Mundo. Sentir-se parte da torcida e compartilhar momentos de entretenimento ao lado dos amigos e familiares incidiu fortemente na motivação das pessoas para comparecerem as "festas" da FIFA em São Paulo.

A confirmação dessa proposição reforça as ideias defendidas por Claussen, Ko, \& Rinehart (2008) que apregoam, nas estratégias mercadológicas, a combinação, através das teorias da diversidade cultural, entre o global e o local. 
Tais autores entendem que o planeta hoje, em uma visão global, não pode ser marcado por uma sociedade unidimensional homogêneo, unida apenas pelos laços de consumo. Apesar de fazer parte de uma estratégia mercadológica global, as FIFA Fan Fests, pela presença de artistas locais, integra elementos das culturas global e local. É o local dentro do global; a porção dentro do conjunto; a diferença na integração; a pluralidade dentro da homogeneidade.

O principal fator motivacional para a presença de público nas Fan Fests, em primeiro plano, foi a sociabilização, ou seja, as relaçóes sociais que o ambiente proporcionou aos seus frequentadores. A presença do entretenimento e a identificação com o local e com o evento também foram elementos apontados como fortes indutores para a frequência ao evento.

\section{Conclusões}

As dimensões do PAS - Place Attachement Scale foram utilizadas para mensurar os fatores que motivaram indivíduos a frequentar as FIFA Fan Fests da cidade de São Paulo, durante a Copa do Mundo 2014, em jogos da seleção brasileira.

O futebol, como demonstrado, não foi o principal elemento de motivação para um indivíduo ir a FIFA Fan Fest paulistana. O entretenimento e a socializaçáo proporcionados pelo evento ocuparam local de destaque como os grandes indutores da presença de público nas "festas". Se divertir e senti parte da torcida foram prioritários. Assistir à partida, secundário.

Tal fato evidencia que náo somente o futebol como outros produtos da indústria do esporte podem ser revestidos de outros formatos para conquistar e atrair audiência e consumidores. Basta apenas que os outros elementos, como àqueles ligados ao entretenimento, à sociabilização e ao consumo, estejam presentes.

Os resultados obtidos sinalizam que o publico que procurou as Fan Fests da FIFA para assistir a uma partida de futebol da Seleção Brasileira em São Paulo buscou não somente ver o jogo, mas também se divertir, através dos meios de entretenimento que foram uma das premissas das Fan Fests.

O estudo permitiu, também, a confirmação que o PAS - Place Attachement Scale, utilizado por Budruk (2010), é consistente em mensurar as relaçóes que pessoas constroem com lugares, seja um estádio, uma sala de cinema, uma praia, um parque nacional ou espaço público qualquer. Porém, é importante ressaltar que, no estudo de Budruk (2010), foi realizada uma comparação de vínculo com locais de culturas distintas. Esse procedimento foi distinto do utilizado neste artigo.

Os resultados obtidos permitem concluir que, quando o $P A S$ é executado em um único local, sem comparações culturais ou de grupo distintos, as suas dimensôes se conectam, formando fatores multidimensionais sobre os motivos que levam indivíduos a determinados locais, neste caso, às FIFA Fan Fest 2014 de São Paulo.

Os resultados evidenciam que a realização das Fun Fests pela FIFA pode ocorrer não somente no país onde a Copa é realizada, mas em qualquer capital do mundo. Uma vez que estar com os amigos com a finalidade de se divertir se 
sobressai ao assistir à partida, o consumo do jogo de futebol como produto de entretenimento fica acima do próprio esporte. Assim, é possível gerar momentos de consumo da Copa do Mundo e dos seus patrocinadores, produzindo um ambiente propicio para isso, mesmo longe do evento em si.

Ainda gerencialmente os resultados trazem a possibilidade para os gestores do esporte no Brasil de criar eventos em suas arenas vinculados a jogos importantes, como por exemplo, trazer a torcida para assistir a uma final de libertadores que ocorre a quilômetros de distância em suas arenas. Ou ainda em locais de alta identificação com os torcedores.

Assim, para pesquisas futuras, o Place Attachement Scale pode ser utilizado na comparação do vínculo de um mesmo local com grupos distintos ou sua aplicação em estudos futuros dos consumidores das FIFA Fan Fests em outros países e em outras ediçốes da competição, como Rússia 2018 ou Catar 2022.

\section{Referências bibliográficas}

ARNOULD, Eric J.; THOMPSON, Craig J. Consumer Culture Theory (CCT): Twenty Years of Research, Journal of Consumer Research, 31 (4), pp. 868-882, 2005.

BELK, Russell W.; WALLENDORF, Melanie; SHERRY, John F. Jr. The Sacred and Theodicy the Profane on in Consumer Behavior: the Odyssey. Journal of Consumer Research, 16 (1), pp.1-38, 2006.

BAUDRILLARD, Jean. A Transparência do mal: ensaio sobre fenômenos extremos. Campinas: Papiru, 1992.

University, 1994. . Simulacra and Simulation. Michigan : Michigan

BAUMAN, Zygmunt. Modernidade Líquida. Rio de Janeiro: Jorge Zahar, 2001.

BORGES, Fernando. O Papel da Fifa Fan Fest TM na Copa do Mundo da África do Sul. Horizontes Antropológicos, 19 (40), 201-230, 2013.

BUDRUK, Megha. Cross-Language Measurement Equivalence of the Place Attachment Scale : A Multigroup Confirmatory Factor Analysis Approach. Joural of Leisure Research, 42(1), 25-42, 2010.

CLAUSSEN, Cathryn L.; Ko, Yong J.; Rinehart, Robert E. Cultural Diversity: an Alternative Approach to Understanding Sport Participant Consumer Behavior. The Smart Journal, 4, 2, 58-71, 2008.

DEBORD. Guy. Society of the Spectacle. London: Black \& Red, 2000.

EBC. Praia de Copacabana recebeu mais de 1 milhão de pessoas nos jogos da Copa. Disponível em: < http://agenciabrasil.ebc.com.br/geral/ noticia/2014-07/praia-de-copacabana-recebeu-mais-de-1-milhao-de-pessoas-durante-os-jogos-da>. Acesso em 15 jul. 2014.

FEATHERSTONE, Mike. Cultura de Consumo e Pós-Modernidade. São Paulo: Studio Nobel, 1995. 
FIFA. 2014. FIFA World Cup Brazil TM (pp. 1 - 90). Disponível em: <http://www.fi fa.com/mm/document/tournament/fanfest/01/14/09/88/fi fafanfest-faqs.pdf>. Acesso em: 30 out 2014 .

FIFA. FIFA Fan Fest ${ }^{\mathrm{TM}}$. Disponível em: <http://www.fifa.com/worldcup/archive/southafrica2010/organisation/fanfest/international/cities/ city=1030/index.html $>$. Acesso em: 30 out. 2014b.

GIDDENS, Anthony. Modernidade e Identidade. Rio de Janeiro: Jorge Zahar, 2002.

HARVEY, David. Condição Pós-moderna. Rio de Janeiro: Loyola, 1992.

JAMESON, Fredric. Espaço e Imagem - teorias do Pós-Moderno e outros ensaios. Rio de Janeiro: UFRJ, 1995.

MINISTÉRIO DO ESPORTE. Balanço final para as açôes da Copa do Mundo da FIFA Brasil 2014 (6 Balanço). Disponível em: < http:// www.esporte.gov.br/arquivos/assessoriaEspecialFutebol/copa2014/6_ Balanco_Copa_dez_2014.pdf>. Acesso em: 20 mar. 2016.

ROCCO JR, Ary J. A Convergência Cultural, o Marketing de Experiências e as Novas Formas de Consumo do Produto de Entretenimento Futebol (pp. 1-15). In: XXXIV Congresso Brasileiro de Ciências da Comunicação Recife, PE - 2 a 6 de setembro de 2011.

SUMMERS, Jane; MORGAN, Melissa J. Sports Marketing (pp. 117132). Cengage Learning Australia, 2005.

THEODORAKIS, Nicholas D.; WANN, Daniel L.; CARVALHO, Mariana; SARMENTO, Pedro. Translation and Initial Validation of the Portuguese Version of the Sport Spectator Identification Scale. North American Journal of Sychology, 12(1), 67-80, 2010.

WILLIAMS, Daniel R., PATERSON, Michael E., ROGGENBUCK, Joseph W.; WATSON, Alan E.. Beyond the Commodity Metaphor: Examining Emotional and Symbolic Attachment to Place. Leisure Sciences, 14 (I), 29-46, 1992.

WILLIAMS, Daniel R.; VASKE, Jerry J. The Measurement of Place Attachment: Validity and Generalizability of a Psychometric Approach. Forest Science, 49(6), $830-840,2003$. 